\title{
Prevention of osteoporosis in female students based on the Orem self-care model
}

\author{
Nader Sharifi ${ }^{1}$, Fereshteh Majlessi ${ }^{2}$, Ali Montazeri ${ }^{3}$, Davood Shojaeizadeh ${ }^{2}$, Roya Sadeghi ${ }^{4}$
}

${ }^{1}$ Ph.D. Candidate of Health Education and Promotion, School of Public Health, Tehran University of Medical Sciences, Tehran, Iran

${ }^{2}$ Ph.D., Professor, Department of Health Education and Promotion, School of Public Health, Tehran University of Medical Sciences, Tehran, Iran

${ }^{3}$ Ph.D., Professor, Health Metrics Research Center, Institute for Health Sciences Research, ACECR, Tehran, Iran

${ }^{4}$ Ph.D., Associate Professor, Department of Health Education and Promotion, School of Public Health, Tehran University of Medical Sciences, Tehran, Iran

\section{Type of article: Original}

\begin{abstract}
Background: The World Health Organization has introduced osteoporosis as the fourth main enemy of mankind. Self care has served as a new trend in health care.

Objective: Educational intervention for osteoporosis related preventive self care in female university students using the Orem model.

Methods: This study is a controlled filed trial, carried out with female students of Islamic Azad University, Shahrekord Branch, Iran, from October 28, 2014 to November 15, 2016. Two-stage random stratified sampling was performed and the data were collected through a validated questionnaire developed by the researcher for osteoporosis preventive self-care based on the Orem model. The intervention group received education about osteoporosis preventive self-care through two months training, as per the dimensions in the Orem model. For statistical analysis, independent-samples t-test and paired t-test were used in SPSS version 23.

Results: As revealed, mean scores for self-care agency, self-care demand, self-care operation structures and total self-care in the intervention group were significantly different before and after the intervention $(\mathrm{p}=0.014$, $\mathrm{p}<0.001, \mathrm{p}=0.002$, and $\mathrm{p}<0.001$, respectively). Accordingly, educational intervention seems to be effective in promoting self-care for the prevention of osteoporosis. While the control group, showed no significant difference in any of the above-mentioned aspects before and after intervention $(\mathrm{p}=0.90, \mathrm{p}=0.53, \mathrm{p}=0.51$, and $\mathrm{p}=0.97$, respectively).

Conclusion: The results are in favor of the effects of educational intervention on osteoporosis preventive selfcare among female students. It can be suggested that education during a woman's young age, can be very beneficial for the prevention of osteoporosis in the future.

Trial registration: The trial was registered at the Iranian Registry of Clinical Trials (http://www.irct.ir) with the Irct ID: IRCT201510028742N8.

Funding: The authors received no financial support for the research, authorship, and/or publication of this article. Keywords: Osteoporosis, Orem self-care model, Educational intervention
\end{abstract}

\section{Introduction}

Osteoporosis is one of the chronic diseases affecting individuals' lives, especially women, in the community (1). Historically, the term "osteoporosis" first entered medical terminology in France and Germany in the 19th century, as a descriptive term emphasizing the porosity of the histological appearances of aged human bone (2). Bones in humans consist of bone mineral and matrix of bone. The main component of bone mineral is composed of calcium

\section{Corresponding author:}

Professor Dr. Fereshteh Majlessi, Department of Health Education and Promotion, School of Public Health, Tehran University of Medical Sciences, Tehran, Iran. Tel: +98.2188989134, Email: m1395dr@gmail.com

Received: December 18, 2016, Accepted: February 25, 2017, Published: October 2017

iThenticate screening: February 13, 2017, English editing: September 20, 2017, Quality control: October 02, 2017

This article has been reviewed / commented by three experts

(C) 2017 The Authors. This is an open access article under the terms of the Creative Commons Attribution-NonCommercialNoDerivs License, which permits use and distribution in any medium, provided the original work is properly cited, the use is non-commercial and no modifications or adaptations are made. 
and the main component of the matrix is composed of collagen tissue. Osteoporosis is mostly due to calcium loss and degradation of collagen tissue (3). The World Health Organization (WHO) announced osteoporosis along with heart attack, stroke and cancer as the four main enemies of human health (4). Aging and changes in population structure have caused concerns about the potential rise in osteoporosis rate (5). According to the reported studies, 200 million people throughout the world are affected by the disease (6). In 2010, 22 million European women over the age of 50 years ( $22 \%$ of female population) were suffering from osteoporosis (7). Evidence indicates that $35.5 \%$ of Korean women over 50 years (8), and approximately 13 million people in Japan are suffering from osteoporosis (9). Rates of vitamin D deficiency and fractures are high in the Middle East and Africa; in Egypt 53.9\% and 28.4\% are reported respectively for osteopenia and osteoporosis (6). According to available statistics, over 6 million Iranians are affected by osteoporosis (10). Fractures are the most common and serious complications of osteoporosis, reported 1.5 million cases annually in the world (11), imposing up to $\$ 17$ billion on the people and government (12). At age 50, the lifetime risk of hip fracture is within $7-25 \%$, which accounts for nearly $50 \%$ of major fractures due to osteoporosis among European women (7). International studies suggest that by 2050, more than half of femoral head fractures due to low bone mineral density occur in women in Asia (13). While the same rate of hip fractures in the elderly in 1990 was reported from Europe and North America, by 2050, the growing population of the elderly in Latin America and Asia could lead to changes in the geographical distribution of hip fracture, so that the share of Europe and North America is reduced to a quarter of these fractures (2). Although maximum bone mass is developed in utero and reaches completion at the age of 40 years, the greatest mass is formed in adolescence and young adulthood (5). If enough bone is generated at this age, the likelihood of developing osteoporosis will be reduced in old age (14). Since osteoporosis preventive measures begin from a young age in developed countries, estimates for associated disorders are better than that for developing ones (15). Certain strategies are necessary if we are to achieve optimal bone mass during childhood, adolescence and adulthood and at the same time reduce the chance of osteoporosis in later stages of life. Education is considered to be very important to raise awareness about the risk factors and preventive behaviors to help prevent osteoporosis, and delay the onset of the disease in later stages of life (16). Needs for health maintenance, inadequate health care services, unequal availability of health facilities in the community and high cost of health services are the reasons leading to the concept of self-care (17). Self-care is a new trend in health care, which includes health promotion measures by the individual himself or herself. More specifically, the concept refers to whatever activities by the individual for the purpose of health maintenance and promotion, disease prevention and limitation (18). A large number of studies in different countries using different research methods have shown that self-care is the most important form of primary care. Self-care is an integral part of all levels of primary health care and can improve the economic and social health status of the population (19). Dorothea Orem's self-care theory is among the most comprehensive (20). Three concepts are central to Orem's theories: self-care, self-care agency, and basic conditioning factors (21). According to this theory, self-care demand and agency are determining factors in self-care behavior. A person with self-care agency, "can" do for self-care measures; this "ability" while accompanied by "demand" self-care, will become "selfcare behavior" (19). Orem's self-care theory can be very effective in preventing disease, but has received little attention in prevention; therefore, the present study aims to determine the effects of educational intervention on osteoporosis prevention among female students using Orem's theory. The interventions are based on a variety of risk factors for osteoporosis and respective preventive behaviors such as physical activities, nutrition, giving up smoking and enough exposure to sunlight.

\section{Material and Methods}

\subsection{Trial design and participants}

This study was a controlled filed trial that was conducted from October 28, 2014 to November 15, 2016. This before-after controlled filed trial was conducted on female students of Islamic Azad University, Shahrekord branch, Iran. Two groups of female students were selected and randomly assigned to intervention and control groups.

\subsection{Selection criteria}

Inclusion criteria were 18 to 30 -year-old female students who had remained for at least 5 semesters at the university. Exclusion criteria were failure to complete the consent form, intention to transfer to another university or giving up the study, and failure to participate in all educational sessions.

\subsection{Instrument design}

Data collection tool was a valid and reliable questionnaire developed by the researcher for osteoporosis preventive self-care, based on the Orem model. It was a Likert type questionnaire with five scale point responses (strongly disagree, disagree, neither agree nor disagree, agree and strongly agree), and the total score range was within the 51- 
255 range. The questionnaire consisted of three parts; 12 questions on self-care agency, 26 on self-care demand, and 13 on self-care operation. To design the tools, we used key terms including self-care, osteoporosis, and Orem model, and found more than 200 related books and articles published within the years 2000-2015. Then 27 sources were selected and carefully reviewed taking into account and consulting the expert views. Finally, questions related to each area were prepared and necessary revisions in wording, arrangement and scoring were made to suit the designed study. To determine the content validity of the self-care questionnaire, it was distributed among ten professionals to be reviewed, and content validity ratio (CVR) and content validity index (CVI) were then specified. As for reliability, two measures of internal consistency and stability were used, and the questionnaire was randomly distributed among 30 female students of Shahrekord Islamic Azad University, with Cronbach's alpha value found to be 0.90 . To evaluate consistency, test-retest method was used. The questionnaire was filled by the same students two weeks later and Interclass Correction Coefficient Index was found for self-care agency 0.71, self-care demand 0.86 and self-care operation 0.82 . Both reliability and consistency were confirmed.

\subsection{Interventions}

Once we selected the intervention and control groups, obtained their consent forms and ensured that no significant difference existed between them in terms of demographic features, the Orem model-based osteoporosis preventive self care questionnaire was filled by the two groups. The educational content was prepared based on provided data by the participants and literature review. The intervention group received education in self-care for the prevention of osteoporosis based on Orem's self-care model (including aspects of self-care agency, demand and operation) for two months. The educational program included lectures, brainstorming, modeling and distributing educational package. Educational sessions were held weekly for a total of eight sessions over two months. Six months after the completion of intervention, the Orem model-based osteoporosis preventive self-care questionnaire was filled by both intervention and control groups and the data were compared. At this stage, there were 71 and 72 students in the intervention and control group, respectively.

\subsection{Outcomes}

As the results indicate, a significant increase was observed in self-care components and its total score after the intervention, compared to scores prior to it. While in the control group, no significant difference was detected in the components.

\subsection{Sample size}

The sample size was determined through Fleiss method, and taking into account confidence level of $95 \%$ and power level $90 \%$ using software OpenEpi (22). Given the possibility of sample loss, the sample size of 150 students consisting of 75 for intervention and 75 for control was selected.

\subsection{Randomization and blinding}

Two stage stratified random sampling was used. To avoid contact bias between the two groups, intervention and control groups were selected from two different randomly selected faculties. Then we randomly picked a clas s from each department within each faculty and finally, 15-20 female students were randomly selected from each class. There was no possibility of blinding in this study.

\subsection{Statistical methods}

For statistical analysis of the data, independent-samples t-test and paired-samples t-test were used in SPSS version 23.

\subsection{Research ethics}

The proposal for this thesis research was presented to the Ethics Committee of Tehran University of Medical Sciences. The Ethics Committee approved the study with the number IR.TUMS.REC.1394.691 on September 5, 2015. This study was also registered in the Iranian Registry of Clinical Trials (irct.ir) with the ID: IRCT201510028742N8. In this study, for ethical considerations, the participants were informed about the objective, and completed a consent form to participate in the study at baseline; also, they were permitted to leave the study at any time. Educational intervention did not create any danger for the participants. A training course was held for the control group to prevent osteoporosis after the end of the study. 


\section{Results}

In Table 1, the self-care model components in both groups were compared using independent-samples t-test. As revealed, no significant difference was evident prior to intervention between the groups in terms of self-care agency $(\mathrm{p}=0.55)$, self-care demand $(\mathrm{p}=0.61)$, self-care operation $(\mathrm{p}=0.64)$ and total self-care $(\mathrm{p}=0.80)$. After intervention, mean score for self-care agency in the intervention group was 49.68 and in controls was 47.08 which were significantly different $(\mathrm{p}=0.14)$. As for self-care demand, the mean for intervention group was 102.56 and for controls 95.92, indicating a significant difference $(\mathrm{p}=0.001)$. Furthermore, the difference in the means of total selfcare between the groups was statistically significant, i.e., 197.18 for intervention group and 187.04 for controls $(\mathrm{p}=0.005)$. Yet, no significant difference was observed between the means for self-care operation in the two groups; it was 44.94 for the intervention group and 44.04 for the controls $(\mathrm{p}=0.48)$. Table 2 displays the difference between before and after intervention, using paired-samples t-test. As seen, significant differences were observed in self-care agency $(p=0.014)$, demand $(p<0.001)$, operation $(p=0.022)$ and total self-care $(p<0.001)$ in the intervention group. Therefore, it can be suggested that educational intervention is helpful for osteoporosis prevention. While the results indicated no significant difference in self-care agency $(\mathrm{p}=0.90)$, demand $(\mathrm{p}=0.53)$, operation $(\mathrm{p}=0.51)$ and total selfcare $(p=0.97)$ in the control group. As revealed, no significant change occurred to the controls in terms of osteoporosis prevention.

Table 1. Comparison of self-care in intervention and control groups (independent-samples t-test).

\begin{tabular}{|c|c|c|c|c|c|c|}
\hline \multirow[t]{2}{*}{ Variables } & \multicolumn{2}{|l|}{ Before Intervention } & \multirow{2}{*}{$\begin{array}{l}\mathrm{p}- \\
\text { value }\end{array}$} & \multicolumn{2}{|l|}{ After Intervention } & \multirow{2}{*}{$\begin{array}{l}\mathrm{p}- \\
\text { value }\end{array}$} \\
\hline & $\begin{array}{l}\text { Intervention Group } \\
(\mathrm{Mean} \pm \mathrm{SD})\end{array}$ & $\begin{array}{l}\text { Control Group } \\
(\mathrm{Mean} \pm \mathrm{SD})\end{array}$ & & $\begin{array}{l}\text { Intervention Group } \\
(\text { Mean } \pm \text { SD) }\end{array}$ & $\begin{array}{l}\text { Control Group } \\
(M e a n \pm S D)\end{array}$ & \\
\hline $\begin{array}{l}\text { Self-care } \\
\text { agency }\end{array}$ & $47.63 \pm 6.71$ & $47.00 \pm 6.03$ & 0.55 & $49.68 \pm 6.30$ & $47.08 \pm 6.19$ & 0.014 \\
\hline $\begin{array}{l}\text { Self-care } \\
\text { demand }\end{array}$ & $95.75 \pm 9.57$ & $96.67 \pm 12.23$ & 0.61 & $102.56 \pm 11.40$ & $95.92 \pm 11.90$ & 0.001 \\
\hline $\begin{array}{l}\text { Self-care } \\
\text { operation }\end{array}$ & $42.92 \pm 7.41$ & $43.44 \pm 6.43$ & 0.64 & $44.94 \pm 7.76$ & $44.04 \pm 7.61$ & 0.48 \\
\hline $\begin{array}{l}\text { Total self- } \\
\text { care }\end{array}$ & $186.30 \pm 19.16$ & $187.11 \pm 20.67$ & 0.80 & $197.18 \pm 20.93$ & $187.04 \pm 21.49$ & 0.005 \\
\hline
\end{tabular}

Table 2. Comparison of self-care before and after intervention (paired-samples t-test).

\begin{tabular}{|l|l|l|l|l|l|l|}
\hline Variables & Intervention Group & p- & Control Group & p- \\
\cline { 2 - 7 } & $\begin{array}{l}\text { Before } \\
\text { Intervention } \\
\text { vean } \pm \text { SD) }\end{array}$ & $\begin{array}{l}\text { After Intervention } \\
(\text { Mean } \pm \text { SD) }\end{array}$ & & $\begin{array}{l}\text { Before } \\
\text { value } \\
\text { (Mean } \pm \text { SD) }\end{array}$ & $\begin{array}{l}\text { After Intervention } \\
\text { (Mean } \pm \text { SD) }\end{array}$ & \\
\hline $\begin{array}{l}\text { Self-care } \\
\text { agency }\end{array}$ & $47.63 \pm 6.71$ & $49.68 \pm 6.30$ & 0.014 & $47.00 \pm 6.03$ & $47.08 \pm 6.19$ & 0.90 \\
\hline $\begin{array}{l}\text { Self-care } \\
\text { demand }\end{array}$ & $95.75 \pm 9.57$ & $102.56 \pm 11.40$ & $<0.001$ & $96.67 \pm 12.23$ & $95.92 \pm 11.90$ & 0.53 \\
\hline $\begin{array}{l}\text { Self-care } \\
\text { operation }\end{array}$ & $42.92 \pm 7.41$ & $44.94 \pm 7.76$ & 0.022 & $43.44 \pm 6.43$ & $44.04 \pm 7.61$ & 0.51 \\
\hline $\begin{array}{l}\text { Total self- } \\
\text { care }\end{array}$ & $186.30 \pm 19.16$ & $197.18 \pm 20.93$ & $<0.001$ & $187.11 \pm 20.67$ & $187.04 \pm 21.49$ & 0.97 \\
\hline
\end{tabular}

\section{Discussion}

The present study was aimed to determine the effects of educational intervention on osteoporosis prevention in female students, based on the Orem model. As the results indicate, a significant increase was observed in self-care components and its total score after the intervention in the intervention group, compared to scores prior to it. However, this has not been the case with the control group, i.e., no significant difference was detected in the components. Also, the results show a significant increase in self-care agency mean score in the intervention group following the implementation of intervention, while this was not true for the controls. Having compared the self-care agency mean score prior to intervention in the two groups, we observed no significant difference, whereas the same comparison after intervention revealed a significant difference. Results of the current study lent support to the effects of educational intervention on individuals' perception and views about capabilities of making decisions and taking measures leading to self-care against development of osteoporosis. As Burdette demonstrated, education and 
health status serve as facilitative and smoking as inhibitory factors in self-care measures (23). Nazek found that the care given to women in the postpartum period using Orem's self-care model increased the self-care agency of postpartum women (24). Also, a study by Wong showed that interventional strategies that aim at promoting self-care behaviors among adolescent girls with dysmenorrhea should strengthen girls' self-care agency (25). With regard to self-care demand, results were indicative of a significant increase in the intervention group following the intervention, however, this was not the case with the control group. No significant difference was evident prior to intervention between the two groups, but the difference was significant after the intervention. Demand is defined as the series of required measures for the satisfaction of all the needs within a certain period in order for the self care to be fulfilled. The ability of the individual, if integrated with self-care demand, can facilitate the underlying factors, and does not hinder the demand, leading to self-care behavior (19). Baghersad demonstrated, that if the educational programs are planned based on needs assessment, the learners follow the educational materials, related to their problems, more seriously and it results in a notable behavior change in them (26). The results also suggest that selfcare mean scores significantly increased following the intervention, depending on the individual's perception of health value, its benefits, the obstacles and social support. However, no such increase was observed in the controls. Omatreza demonstrated that self-care education based on the Orem model and patients' needs for self-care, resulted in improved life quality of those with migraine (27). As for self-care operation, the results imply a significant increase in the respective mean score following the intervention in the treatment group while this was not true for the control group. It is worth mentioning that no significant difference in self care operation was evident between the two groups pre- and post-intervention. According to the Orem model, self-care agency and demand are determining factors for the realization of self-care behavior in the individuals. In other words, if such a behavior is to take place, the individual should be willing and capable, and appropriate underlying conditions must be present. As Naji reported, use of the Orem model is very helpful to the improvement of self-care behavior, reduced hospitalization and admission or referrals, and also balance in fluid intake in patients with heart problems (28). Zarandi concluded that performing Orem's self-care model improves function and overall quality of life and reduces the high cost of a migraine and migraine-related disability to individuals and society (29), also based on a Hashemi study, designing and implementing a self-care strategy based on Orem's model and the needs of burns patients will improve their quality of life (30). Lack of significant difference between the two groups in the present study could be attributed to the required presence of some facilitating factors for the realization of certain behaviors. Burdette showed that investment in such factors and minimizing inhibiting factors of self-care performance can be helpful to the intervention aimed at those with obesity. In addition, occupation and health status serve as facilitators while smoking and chronic diseases act as barriers to effective self-care performance (23). This study found that education based on Orem's self-care is effective for the prevention of osteoporosis. To be noted is the limitation to generalize the findings to other age groups because the target group of this study were female students.

\section{Conclusions}

Overall, the present study results are in favor of the effects of educational intervention on osteoporosis preventive self-care among the female students of Islamic Azad University, Shahrekord branch. It can be suggested that education during young adulthood, especially in women, can be very beneficial for the prevention of osteoporosis in the future. Further studies addressing osteoporosis preventive self-care based on the Orem model and taking into account the influential social and underlying factors are warranted.

\section{Acknowledgments:}

The data in this article are partially based on the $\mathrm{PhD}$ thesis from the Health Education and Promotion Division of the School of Public Health, Tehran University of Medical Sciences, code 9121108008.

\section{Trial Registration:}

The trial was registered at the Iranian Registry of Clinical Trials (http://www.irct.ir) with the Irct ID: IRCT201510028742N8.

\section{Funding:}

The authors received no financial support for the research, authorship, and/or publication of this article.

\section{Conflict of Interest:}

There is no conflict of interest to be declared. 
Authors' contributions:

All authors contributed to this project and article equally. All authors read and approved the final manuscript.

\section{References:}

1) Ghaffari M, Tavassoli E, Esmaillzadeh A, Hasanzadeh A. The Effect of Education based on Health Belief Model on theimprovement of osteoporosis Preventive Nutritional Behaviors of SecondGrade Middle School Girls in Isfahan. J Health Research System 2010; 6(4): 1-10.

2) Holroyd C, Cooper C, Dennison E. Epidemiology of osteoporosis. Best Practice \& Research Clinical Endocrinology \& Metabolism. 2008;22(5):671-85. PMID: 19028351. doi: 10.1016/j.beem.2008.06.001

3) Kurt-Sirin O, Yilmaz-Aydogan H, Uyar M, Seyhan M-F, Isbir T, Can A. Combined effects of collagen type I alpha1 (COL1A1) Sp1 polymorphism and osteoporosis risk factors on bone mineral density in Turkish postmenopausal women. Gene. 2014;540(2):226-31. PMID: 24566004. doi: 10.1016/j.gene.2014.02.028

4) Tavakoli MB, Salamat MR, Tavakoli M. Comparative study of the density of L2, L3, and L4 vertebrae in menopausal women aged over 50 years with osteoporosis. Journal of education and health promotion. 2015;4. PMCID: PMC4456881.

5) Lane NE. Epidemiology, etiology, and diagnosis of osteoporosis. American journal of obstetrics and gynecology. 2006 Feb 28;194(2):S3-11. PMID: 16448873. doi: 10.1016/j.ajog.2005.08.047

6) El-Tawab SS, Saba EKA, Elweshahi HMT, Ashry MH. Knowledge of osteoporosis among women in Alexandria (Egypt): A community based survey. The Egyptian Rheumatologist. 2015. Doi: 10.1016/j.ejr.2015.08.001.

7) Rizzoli R, Stevenson JC, Bauer JM, Van Loon LJ, Walrand S, Kanis JA, et al. The role of dietary protein and vitamin $\mathrm{D}$ in maintaining musculoskeletal health in postmenopausal women: a consensus statement from the European Society for Clinical and Economic Aspects of Osteoporosis and Osteoarthritis (ESCEO). Maturitas. 2014 Sep 30;79(1):122-32. PMID: 25082206. doi: 10.1016/j.maturitas.2014.07.005

8) Ryu K-J, Park H-T, Kim YJ, Yi KW, Shin JH, Hur JY, et al. Vasomotor symptoms and osteoporosis in Korean postmenopausal women. Maturitas. 2016;87:27-32. PMID: 27013285. doi: 10.1016/j.maturitas.2016.02.007

9) Iwamoto Y, Uchida K, Sugino N, Kuroiwa H, Kitamura Y, Udagawa N, Shinohara A, et al. Osteoporosis, osteoporotic fractures, and carotid artery calcification detected on panoramic radiographs in Japanese men and women. Oral surgery, oral medicine, oral pathology and oral radiology. 2016 Jun 30;121(6):673-80. DOI: 10.1016/j.000o.2016.02.006.

10) Sharifi N, Majlessi F. Self-Empowerment of Female Students in Prevention of Osteoporosis. Global Journal of Health Science. 2016 Jun 30;9(2):7. Doi: 10.5539/gjhs.v9n2p7.

11) Forouzi MA, Haghdoost AA, Saidzadeh Z, Mohamadalizadeh S. Study of knowledge and attitude of Rafsanjanian female teachers toward prevention of osteoporosis. Journal of Birjand University of Medical Sciences. 2009 Mar 1;16(1):71-7.

12) Huth PJ, Dirienzo DB, Miller GD. Major scientific advances with dairy foods in nutrition and Health. J Dairy Sci 2006; 89(4): 1207-21. PMID: 16537954. doi: 10.3168/jds.S0022-0302(06)72190-7

13) Fujiwara S. Epidemiology of osteoporosis. clin calcium. 2005;15(4):577-582. PMID: 15802768.

14) Iranian Rheumatology Association. osteoporosis. 2010. Available from: http://www.iranianra.ir

15) Gurney S, Simmonds J. Osteoporosis: a teenage perspective. Physiotherapy. 2007 Dec 31;93(4):267-72. DOI: 10.1016/j.physio.2006.12.004.

16) Papadopoulos L. Osteoporosis prevention education for adolescents: a systematic review of the literature (Doctoral dissertation, Auckland University of Technology).

17) Mohammad Hassani MR, Farahani B, Zohour AR, Panahi Azar Sh. Self-care ability based on Orem's theory in individuals with coronary artery disease. Journal of Critical Care Nursing. 2010 Jul 15;3(2):15-6.

18) Dashiff CJ, McCaleb A, Cull V. Self-care of young adolescents with type 1 diabetes. Journal of pediatric nursing. 2006 Jun 30;21(3):222-32.PMID: 16713512. doi: 10.1016/j.pedn.2005.07.013

19) Rafieifar SH, Atarzadeh M, Ahmadzad-Asl M. Comprehensive system of empowering people to take care of their own health. Frontierless Researchers Institute; 2005:15-95.

20) VASILIEVA IA. Quality of life in chronic hemodialysis patients in Russia. Hemodialysis International. 2006 Jul 1;10(3):274-8. PMID: 16805889. doi: 10.1111/j.1542-4758.2006.00108.x

21) Baker LK, Denyes MJ. Predictors of self-care in adolescents with cystic fibrosis: A test of Orem's theories of self-care and self-care deficit. Journal of pediatric nursing. 2008 Feb 29;23(1):37-48. doi: 10.1016/j.pedn.2007.07.008, PMid: 18207046 
22) Dean AG, Sullivan KM, Soe MM. OpenEpi: Open source epidemiologic statistics for public health, version. Availabe from: www. OpenEpi. Com. 2014.

23) Burdette L. Relationship Between Self-care Agency, Self-care Practices and Obesity among Rural Midlife Women. Self Care Depend Care Nurs. 2012;19(1):5-14.

24) Nazik E, Eryilmaz G. The prevention and reduction of postpartum complications: Orem's Model. Nursing science quarterly. 2013 Oct;26(4):360-4. PMID: 24085674. doi: 10.1177/0894318413500402

25) Wong CL, Ip WY, Choi KC, Lam LW. Examining Self - Care Behaviors and Their Associated Factors Among Adolescent Girls With Dysmenorrhea: An Application of Orem's Self - Care Deficit Nursing Theory. Journal of Nursing Scholarship. 2015 May 1;47(3):219-27. PMID: 25801754. doi: 10.1111/jnu. 12134

26) Baghersad Z, Alimohammadi N, Boroumandfar Z, Golshiri P. Effect of self-care training program based on Orem's model on the behaviors leading to sexually transmitted disease in vulnerable women. Iranian Journal of Nursing and Midwifery Research. 2016 Sep;21(5):527. doi: 10.4103/1735-9066.193418, PMCid: PMC5114800, PMID: 27904639.

27) Omatreza S, Moshtagh Eshgh Z, Eshagh M, Hekmatafshar M, Naieni MK. Effect of educational program based on" Orem Self Care Model" on quality of life in patients with migraine. Journal of Health Promotion Management. 2014 Jan 15;3(1):7-13.

28) H, Nikhbakht Nasrabadi A, Shaban M, Saebnia R. The effect of using Orem's model of self-care on recovery of patients with heart failure. Iranian Journal of Nursing and Midwifery Research. 2010 Jun $1 ; 14(4)$.

29) Zarandi FM, Raiesifar A, Ebadi A. The Effect of Orem's Self-Care Model on Quality of Life in Patients with Migraine: a Randomized Clinical Trial. Acta Medica Iranica. 2016 Mar 1;54(3):159-64. PMID: 27107519.

30) Hashemi F, Dolatabad FR, Yektatalab S, Ayaz M, Zare N, Mansouri P. Effect of Orem Self-Care program on the life quality of burn patients referred to Ghotb-al-Din-e-Shirazi burn center, Shiraz, Iran: a randomized controlled trial. International journal of community based nursing and midwifery. 2014 Jan;2(1):40. PMID: 25349844. PMCid:PMC4201185 